\title{
Kernos
}

Revue internationale et pluridisciplinaire de religion grecque antique

3| 1990

Varia

\section{Marcel DETIENNE et Giulia SISSA, La vie quotidienne des dieux grecs}

Vinciane Pirenne-Delforge

\section{OpenEdition \\ Journals}

\section{Édition électronique}

URL : http://journals.openedition.org/kernos/1028

DOI : 10.4000/kernos. 1028

ISSN : 2034-7871

\section{Éditeur}

Centre international d'étude de la religion grecque antique

Édition imprimée

Date de publication : 1 janvier 1990

ISSN : 0776-3824

\section{Référence électronique}

Vinciane Pirenne-Delforge, "Marcel DETIENNE et Giulia sISSA, La vie quotidienne des dieux grecs », Kernos [En ligne], 3 | 1990, mis en ligne le 19 avril 2011, consulté le 24 septembre 2020. URL : http:// journals.openedition.org/kernos/1028; DOI : https://doi.org/10.4000/kernos.1028 
la fécondité et à la fertilité (Déméter et Dionysos) et enfin «la divinité grecque par excellence, Apollon». Pareille classification ne peut certes prétendre épuiser toute la riche diversité de la mythologie antique, mais elle permet au moins d'en faire voir des traits essentiels; si elle entraîne quelques redites et conduit parfois à accentuer tels aspects de certains mythes au détriment d'autres, elle offre l'avantage d'une mise en perspective éclairante qui intègre l'apport de nombreux travaux modernes.

Brièvement introduits et suivis d'une conclusion récapitulative, les chapitres sont illustrés par de nombreux extraits de poètes anciens, sobrement annotés et commentés avec compétence; ils sont aussi accompagnés d'une bibliographie sommaire dont la plupart des titres sont en langue française. Diverses annexes enrichissent l'ouvrage; elles comprennent notamment un tableau des grandes divinités, avec indication de leurs symboles, de leurs fonctions et de leurs principaux lieux de culte, des tableaux généalogiques, un index des auteurs anciens cités, un index des noms propres ainsi qu'une table des illustrations; abondantes, mais d'un format qui paraîtra souvent trop réduit, les représentations, en noir et blanc, sont puisées pour la plupart dans le trésor de l'iconographie gréco-romaine.

Voici donc un ouvrage de haute vulgarisation scientifique qui non seulement se prête à la consultation, mais qui invite aussi à la lecture. On doit lui souhaiter une large audience, car il contribue à faire mieux comprendre la mythologie antique dans la dimension religieuse qui la caractérise au départ, dans la réflexion permanente sur l'homme, la société et le monde qu'elle reflète, dans la vitalité aussi qu'elle conserve au sein de la culture occidentale. Les spécialistes ne doivent pas s'attendre à y découvrir de grandes nouveautés, mais ils y trouveront souvent matière à réflexion et ils ne seront pas davantage insensibles au plaisir que procure la lecture d'une œuvre bien écrite, que recommandent aussi son ordonnance méthodique ainsi que sa présentation soignée.

André MOTTE

Marcel DETIENNE et Giulia SISSA, La vie quotidienne des dieux grecs, Paris, Hachette, 1989, 301 p., 12 pl., 2 cartes, 13 x 20 cm. Prix : 118 FF.

L'Iliade d'Homère autorise, d'après les A., l'écriture d'une Vie quotidienne des dieux et donc l'insertion de cet ouvrage au sein de la collection Hachette du même nom. Dès lors, toute la première partie, intitulée "Homère anthropologue", est une lecture attentive du récit de la Guerre de Troie dans le but de disséquer au jour le jour l'existence de la société des Immortels : sentiments, besoins, morphologie, occupations, exercice du pouvoir et rapports aux hommes sont étudiés à travers les différents épisodes, petits et grands, du récit homérique. L'anthropo- 
morphisme régnant justifie pleinement les qualités d'«anthropologue» attribuées à l'auteur grec! Les critiques des philosophes anciens, parmi lesquels Épicure reçoit un traitement de faveur, viennent adroitement donner à l'exposé une profondeur chronologique qui se referme sur les Pères de l'Église et leur Dieu créateur.

Cette lecture, qui est aussi réécriture, due à Giulia Sissa, éclaire le texte d'Homère d'un jour - et le terme convient ici dans ses deux acceptions ! - très agréable, même s'il n'est pas vraiment nouveau, et ce voyage au pays des dieux grecs ne dispensera de toute façon pas d'y suivre Homère en personne.

Dans la deuxième partie, Marcel Detienne pose la question de savoir ce que deviennent les Olympiens dans le temps des hommes. Sont-ils aussi envahissants dans la cité que dans l'épopée ? La réponse est mitigée : les dieux impliqués dans bon nombre des comportements du citoyen, certainement; des hommes assujettis aux puissances divines, assurément non. Le titre choisi est révélateur de ce point de vue : "Les dieux au plaisir de la cité», car s'ils règnent, ils ne gouvernent pas. Ce constat, jadis posé par L. Gernet et A. Boulanger, le tableau vivant, coloré et comme toujours très bien documenté du polythéisme de la Grèce des cités revu par Marcel Detienne, vient encore le confirmer. Et son exposé de s'achever sur la présentation du rôle de divinités féminines dans la formation des citoyens (Héra à Argos et Athéna à Athènes) et sur la mise en perspective d'un Dionysos - l'«enfant chéri» de l'A. ! - bel et bien présent dans la vie civique sous la forme d'un phallus, qui signifie l'élan de la force vitale et évoque, implicitement, la pérennité du groupe social.

Au total, un ouvrage plaisant, dont le style enlevé - émaillé de jeux de mots et d'expressions parfois surprenantes (p. 262: "Comme le train de nos passages à niveau, un phallus peut en cacher un autre») confirme le talent de nos auteurs pour «raconter» les derniers développements d'une discipline scientifique qui, sous leur plume, n'a plus rien d'austère! La vulgarisation atteint ici un très haut niveau, même si des esprits chagrins ne manqueront pas d'épingler les raccourcis inhérents à ce genre littéraire difficile.

Vinciane PIRENNE-DELFORGE

Anna KOFKOU, Crète. Tous les musées et les sites archéologiques, Athènes, Ekdotikè Athènon, 1989, 288 p., 358 ill. couleurs, 2 cartes, 24 x 17 $\mathrm{cm}$. (Traduction française due à $\mathrm{B}$. de Tournay).

Ce nouveau guide de Crète, magistralement illustré, retiendra l'attention de ceux qui s'intéressent aux croyances et aux pratiques religieuses crétoises. 